\title{
Prototype Development of ADI 1.0 (Animal Disease Information) to Increase Social Awareness in Indonesia
}

\author{
Fitriyyah Shalihati \\ School of Business \\ IPB University Bogor Agricultural \\ University) \\ Bogor, Indonesia \\ fitriyyah.shalihati@apps.ipb.ac.id line
}

\author{
Nur Hasanah \\ School of Business \\ IPB University (Bogor Agricultural \\ University) \\ Bogor, Indonesia \\ nur.hasanah@apps.ipb.ac.id
}

\author{
Dikky Indrawan \\ School of Business \\ IPB University (Bogor Agricultural \\ University) \\ Bogor, Indonesia \\ rdikky@apps.ipb.ac.id
}

\begin{abstract}
The increasing zoonoses threat every year, such as swine influenza, avian influenza, monkeypox, and other exotic pathogenic microbes, have caused social unrest. This unrest results in many people trying to quickly find information online as their guide to control and avoid the impact of the disease outbreak. However, there is limited digital information available online at the beginning of the outbreak. This study aims to develop a prototype of an animal disease information system as a mean of increasing public awareness towards zoonoses threats. The digital platform was developed as a smartphone application or apps. This app was called ADI 1.0 (Animal Disease Information) that contains information on animal diseases, the origin of animal diseases, the first location of the outbreak, countries with travel warrant, the first aid and casualties handling, and other related information. ADI 1.0 was designed to support and connect the government, veterinary experts, and society to provide up-to-date and real-time information. In the future, it will be linked to an early warning system, so that the users of ADI 1.0 can have a better awareness and control of a zoonosis outbreak. The developed prototype will support major media platforms in this digital era and provide necessary zoonoses information as a means of increasing social awareness
\end{abstract}

Keywords - Prototype, apps, digital media, digital platform, zoonotic disease, social awareness

\section{INTRODUCTION}

There is a growing concern of the increasing threat of zoonoses, the diseases that have jumped species from animals to people, which have caused social unrest mainly in developing countries, including Indonesia. The World Health Organization estimates there are 200 different zoonoses, causing 100,000 deaths globally each year [1]. An influential 2012 study by researchers from the International Livestock Research Institute estimated that around $60 \%$ of all human diseases are zoonotic, and in the least developed countries, $20 \%$ of all human sickness and death are due to zoonoses [2].

According to the Ministry for Human Development and Cultural Affairs, the Indonesian government has determined five top priorities of zoonosis in Indonesia: rabies, avian influenza, leptospirosis, brucellosis, and anthrax. These diseases are prioritized because they often cause loss of life as well as economic losses of enormous value every year [3].
Diseases arise not only from individuals but also from the environment. The occurrence of the disease is influenced by many factors. Therefore, the solution is not only multidisciplinary but transdisciplinary. An overall approach from expertises, ministries, and all corresponding sectors is needed to collaborate in solving this problem.

'One Health' is an approach to designing and implementing programs, policies, legislation, and research in which multiple sectors communicate and work together to achieve better public health outcomes. Cross-sectoral collaboration is key to understanding and managing public health risks at the human-animal-environment interface and improving global health security. One of the WHO programs regarding One Health is the development and promotion of practical, evidence-based, and cost-effective tools and mechanisms for zoonoses prevention, surveillance, detection, and reporting [1].

Precautions against animal diseases are needed. Using effective methods to increase awareness of preventable zoonosis diseases are key components of the One Health system. A study by Hasanov et al. (2018) [4] revealed that a relatively simple awareness campaign to the community was effective at improving knowledge of the symptoms and vaccination schedules of a certain zoonosis, rabies. The study suggested optimizing the information channels used to distribute information about the disease.

Nowadays, many people in the open era of Industry 4.0 rely on the mobile-based information for animal disease information. The development of mobile-based platform has disrupted the previous old ways of business and consumer ecosystem. The term VUCA is getting more popular in recent years, which describes the current business ecosystem that is volatile, full of uncertainty, complex, and ambiguous. As for the consumer ecosystem, the acronym of VUCA stands for vibrant, unreal, crazy, and astounding [5]. Consumers nowadays have certain expectations of the service they are using, namely fast, entertaining, transparent, seamless, and personal. High acceptance of mobile phones and the Internet around the world has provided increasing opportunities in crowdsourcing, where a big number of people are working together to tackle a problem [6]. Mobile phones are promising medium for this opportunity since they are carried anywhere, can be used at any time, and even can function in remote locations [7]. 
The integration of healthcare-related information and tasks using mobile platform is a benefit for big data. Leveraging big data will help accomplish One Health goals in a shorter time with minimum cost for the environment, healthy people and animals [8]. The vast amount of health data will accelerate the diseases' real-time tracking, outbreaks prediction, and healthcare development.

The social unrest caused by the zoonosis threat and the specific consumer behavior in the VUCA era results in consumers trying to quickly find information online as their guide to control and avoid the impact of the disease outbreak. However, there is limited digital information available online at the beginning of the outbreak. Building a mobile-based platform that is compatible with the business ecosystem and the current ecosystem of VUCA consumers is a way to optimize the information channel for zoonosis diseases.

The importance of a mobile-based platform in relation to health promotion has been previously investigated. Neiger et al. (2012) [9] asserted that health promotion efforts to engage diverse audiences such as minority populations and adolescents might be most successful if they involve social media applications that interface easily with mobile devices. The use of social media can help provide a voice for disproportionately affected audiences and provide better access to those in need of programs and services.

The World Organisation for Animal Health (OIE) had started utilizing the mobile app to increase public awareness by launching WAHIS Alerts mobile app in May 2016 [10]. The app delivers disease alerts (immediate notifications) and OIE follow-up reports from the World Animal Health Information System (WAHIS) directly to the user's mobile phone or tablet. Users can choose to receive only those notifications and reports related to the regions and diseases that interest them, thus enabling them to keep up to date with the most relevant latest health news.

The Ministry of Agriculture of Victoria, US, had recently launched an app called "Notify Now" in June 2019 [11]. The app allows users to send high-quality geo-located photographs of the affected animals, with the owner's details and Property Identification Code directly to the Chief Veterinary Officer. If required, users can also call the Disease Watch Hotline number through the app.

Both the WAHIS Alerts and Notify Now app focused mostly on the outbreak reporting feature. Unfortunately for the Indonesian community, the apps are only available in certain languages (English, French, or Spanish). This study aims to develop a prototype of an animal disease information system as a mean of increasing public awareness towards zoonoses threats for Indonesian community. In addition to outbreak reporting feature, the mobile app will provide related information regarding zoonosis descriptions, information from governments and veterinarians, and other related information.

\section{MATERIAL AND METHODS}

Our prototype development was based on a combined approach of mobile platform software development and consumers' behavior approach. The main goal of this approach was to ensure the application will be accepted by the users and information seekers. The Technology Acceptance Model (TAM) [12] explained that the acceptance of an information system for an individual is determined by two main variables, namely perceived usefulness and perceived ease of use. According to this model, it is expected that the factor that influences the intention to use an information system the most is the perceived usefulness of a tool. Therefore, it is crucial to construct our information system based on users' needs to elevate the usefulness of the system.

The development of the Animal Disease Information system is started by the first step in the Customer Development Process [13], as depicted in Fig. 1. The Customer Development Process consists of iteration process (customer discovery and customer validation) and execution process (customer creation and company building). In this study, we focused on the first iteration of customer discovery and customer validation.

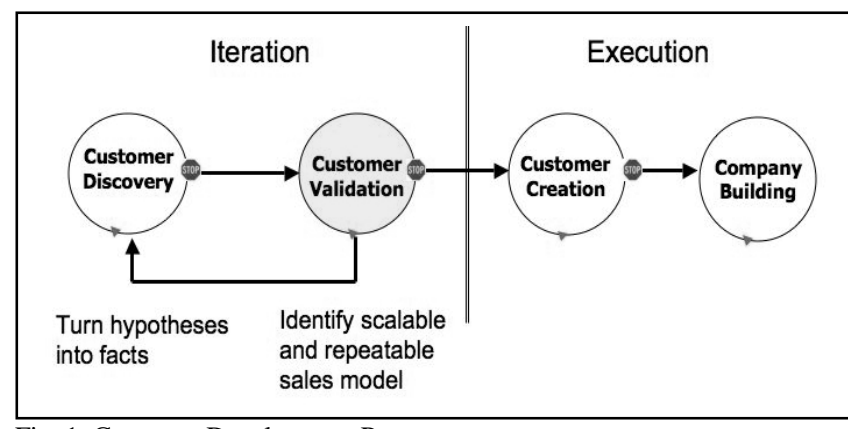

Fig. 1. Customer Development Process

In the initial stage, insights from the respondents are needed to develop the ideas, such as how big is the need for the development of this zoonosis mobile platform and what kind of feature is expected to be developed in this system.

Data collection was conducted through in-depth interviews with ten people who are accustomed to using mobile platforms. Respondents for the first iteration are potential customers who represent today's digital consumers, consisting of millennial college students, web and apps developers, as well as graduates of Faculty of Veterinary Medicine, IPB University.

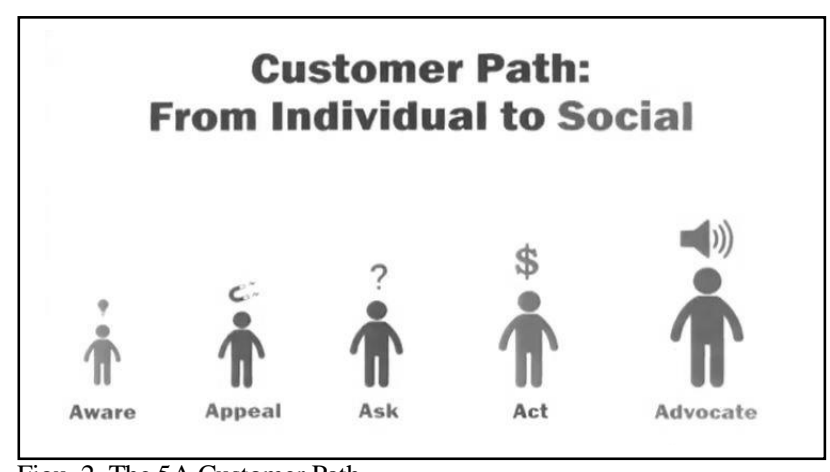

Figu. 2. The 5A Customer Path

From the interview, we focused on the $5 \mathrm{~A}$ customer path, illustrated in Fig. 2, as the approach for increasing public awareness of zoonosis through our system. The 5A customer path, namely Aware, Appeal, Ask, Act, and Advocate [14], describes a customer journey in the era of a technology-driven connected world, where it is no longer a straightforward funnel-like process as in the previous era, 
and it is neither a personal journey. Digital connectivity enables a company to reach out to the customers more easily with less effort, and interaction between customers is now defining the rapid growth, or in the opposite, the subordinate development of a brand. Defining the $5 \mathrm{~A}$ customer path for our system is necessary to ensure proper suit between our system's features and customer needs.

Following the Design Thinking process [15], as illustrated in Fig.3, the next step after conducting a deep interview to empathize with the potential users and define users' needs is to ideate the system features and build the prototype of the system. Through the prototype test, the developer will find out whether the implemented solutions have been successful. The result will be used to redefine one or more of the system features and to build a better understanding of the users' problems when interacting with the system.

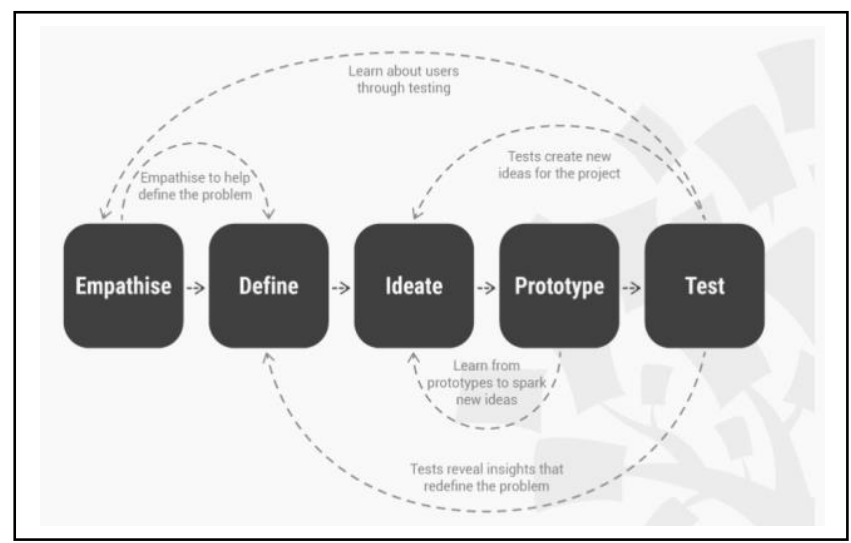

Fig. 3. Design Thinking Process

\section{RESULTS}

From the in-depth interview with ten respondents, we found that all of them believed that the Animal Disease Information (ADI) system needs to be developed to answer the necessity of a way to obtain comprehensive information about animal diseases that is easy to access using mobile platform. Among the respondents, seven of them expressed the needs of this app to help their activities because they often travel to other cities/countries, and having ADI at hand would be useful for them as consideration towards their traveling plan.

Based on the interview, we also synthesized essential features that need to be developed in the ADI 1.0 prototype in the first iteration. The features are information on animal diseases, the origin of animal diseases, location of the outbreak (first location), information from government, information from veterinary experts, countries with travel warrant, first aid and casualties handling, and other related information. The features are as follows:

1. Information on animal diseases. This feature will give an overview of various animal diseases, both of those that are happening currently and already happened in the past. There are also descriptions of potential diseases that could arise in animals that will need special attention.

2. The origin of animal diseases. The Origin of Animal Diseases provides information about where the animal diseases originated. For example, zoonosis monkeypox was first discovered in 1958 when a group of monkeys that were the subject of research in a laboratory in Cameroon suffered from this illness. The carrier of this virus is mice/rats from Africa (African rodents). The rat bit the animals, transmitted the virus and caused them to get sick. Through these targeted animals, the virus then got transmitted to human.

3. Location of the outbreak (first location). This feature provides information about the origin of the animal disease (the first country/location). For example, monkeypox animal diseases originated from the regions of Central and West Africa. This information will help customers to be more aware when traveling to the area that is the origin of some animal diseases.

4. Information from the government. Information from the government regarding zoonoses will be displayed in this menu, such as Republic of Indonesia Government Regulation Number 3 of 2017 concerning Veterinary Authorities, Number 6 of 2013 concerning Farmer Empowerment, as well as other regulations that complement the knowledge and information needed by the community to increase their awareness.

5. Information from veterinary experts. Information from veterinary experts or veterinary specialists is highly sought, most importantly as a source of accurate information on animal diseases and other related information. In the future, a chat service feature with experts will be developed.

6. Countries with travel warrants. Many countries issued travel warrants to the countries where zoonoses originated to deal with the spread of the disease. Information about which countries issued travel warrants and travel warnings will be provided in this menu.

7. First aid and casualties handling. This information will greatly help people who use the ADI application to find out what needs to be done when there is an indication of the transmission of viruses/bacteria from animal diseases. By using this information, users can conduct the right treatment anywhere and in a fast time after disease transmission is detected.

8. Other related information. The last menu is prepared to provide additional information outside the previous menus, such as related articles provided by experts as well as testimonials from ADI users.

The 5A Customer Path (Awareness, Appeal, Ask, Act, and Advocate) approach for ADI 1.0 that were discovered from in-depth interviews explained respondents' behavior about how they are responding to the new app.

At the Awareness level, respondents are generally aware of the existence of new applications through advertisements. However, since zoonosis is not a widely known subject, there is a need to create a particular advertisement that contains education on the importance of 
public awareness about animal diseases and how to first treat them in order to promote ADI 1.0.

At the Appeal level, respondents were interested in the ADI app because it enables them to get the information needed. At the Ask level, respondents searched for information about animal diseases by browsing the internet, which shows the high curiosity of respondents.

At the Act level, respondents' curiosity drives them to use the ADI app as the source of information about animal diseases. At the Advocate level, respondents will be happy to inform and invite their colleagues to download and use the ADI app.

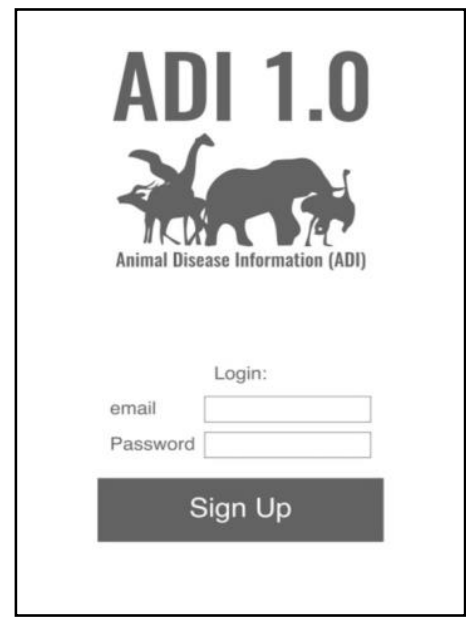

Fig. 4. Prototype 1: The front interface

The prototype interface is shown in the following figures. The front interface, depicted in Fig.4, contains a login menu for recurring users or signup menu for new users. The registration process for new users is required to store users' credentials such as location, which is needed for pushing notifications of disease outbreak in the nearby location, as well as other planned features such as reporting a disease outbreak to the authority.

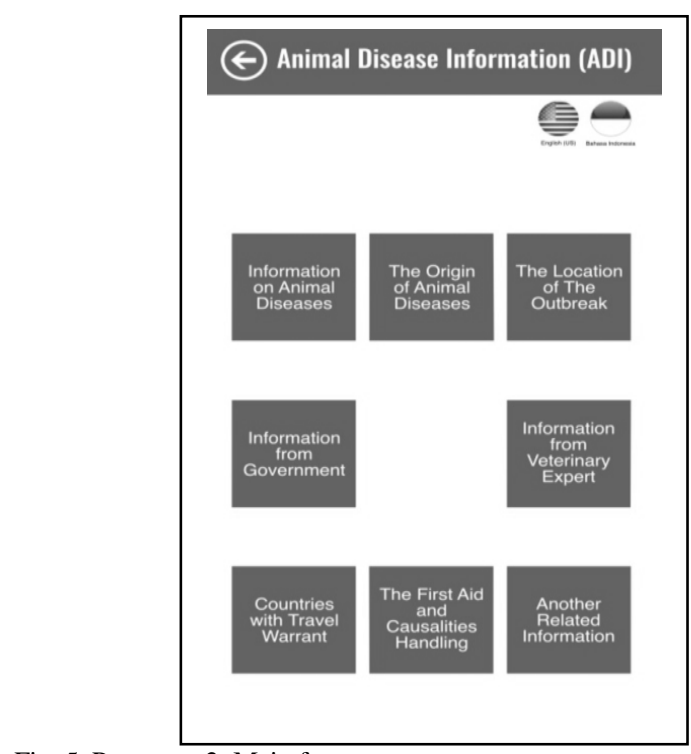

Fig. 5. Prototype 2: Main features

Fig. 5 describes eight comprehensive features based on the first iteration process: Information on animal diseases, the origin of animal diseases, the location of the outbreak (first location), information from government, information from veterinary experts, countries with travel warranties, the first aid and casualties handling, and another related information. Fig. 6 depicts zoonosis information that can be accessed by users, categorized by the animal type.

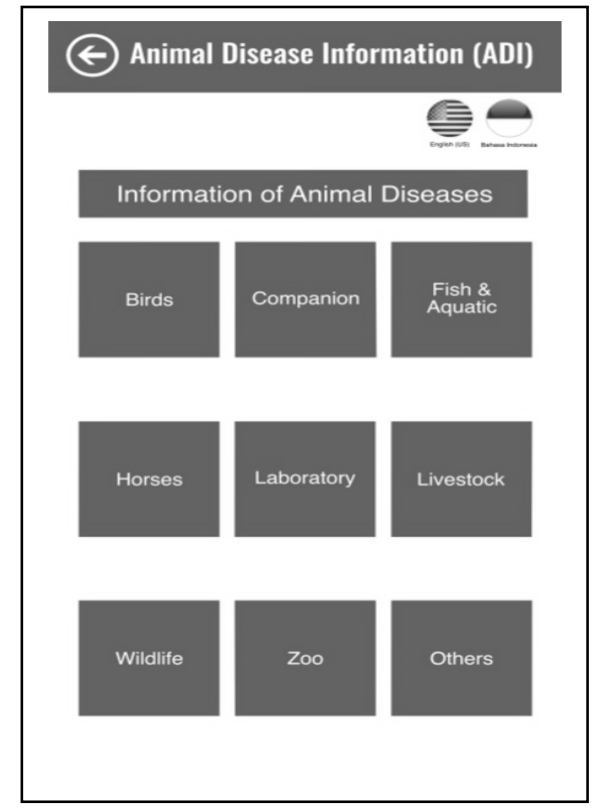

Fig. 6. Prototype 3: Zoonosis information

\section{CONCLUSION}

This study reported the initial development of a mobile application named Animal Diseases Information to facilitate the rapid needs of information of the Indonesian community in the current VUCA era. The prototype of ADI 1.0 (Animal Disease Information) was created based on the first iteration of Customer Development and Design Thinking to produce a user-friendly app according to the needs and wants of potential consumers.

One of the advantages offered by ADI 1.0 is the support of dual language, Indonesian and English. The initial development will be focused on Indonesian language in order to reach the main customers of Indonesian community.

The developed prototype will support major media platforms in this digital era and provide important information related to zoonosis diseases in order to promote social awareness through the customer path 5A. In future development, an early warning system will be incorporated into the system. Therefore, the users of ADI 1.0 will have a better awareness of zoonotic outbreaks and easy access to the essential information authenticated by both the veterinarians and the government.

Further development plan includes an advanced customer development iteration process before reaching the customer development execution stage. Initial findings show that limited awareness of animal diseases and zoonoses were found. It gives a challenge to develop more interactive mobile platform. Moreover, user participation for diseases information are needed to improve available and an update disease information. 


\section{REFERENCES}

[1] WHO. https://www.who.int/zoonoses/en/

[2] Grace, Delia, F. Mutua, P. Ochungo, R. L. Kruska, K. Jones, L. Brierley, Ma Lapar et al. "Mapping of poverty and likely zoonoses hotspots." (2012).

[3] Suara. https://www.suara.com/health/2019/05/14/134057/ini-limapenyakit-bersumber-hewan-yang-berpotensi-wabah-di-indonesia

[4] Hasanov, E., S. Zeynalova, M. Geleishvili, E. Maes, E. Tongren, E. Marshall, A. Banyard et al. "Assessing the impact of public education on a preventable zoonotic disease: rabies." Epidemiology \& Infection 146, no. 2 (2018): 227-235.

[5] Bennett, Nathan, and James Lemoine. "What VUCA really means for you." Harvard Business Review 92, no. 1/2 (2014).

[6] Eysenbach, Gunther. "Infodemiology and infoveillance: framework for an emerging set of public health informatics methods to analyze search, communication and publication behavior on the Internet." Journal of medical Internet research 11, no. 1 (2009): e11.

[7] Waegemann, C. Peter. "mHealth: the next generation of telemedicine?." Telemedicine and e-Health 16, no. 1 (2010): 23-26.

[8] Asokan, G. V., and Vanitha Asokan. "Leveraging "big data" to enhance the effectiveness of "one health" in an era of health informatics." Journal of epidemiology and global health 5, no. 4 (2015): 311-314.
[9] Neiger, Brad L., Rosemary Thackeray, Sarah A. Van Wagenen, Carl L. Hanson, Joshua H. West, Michael D. Barnes, and Michael C. Fagen. "Use of social media in health promotion: purposes, key performance indicators, and evaluation metrics." Health promotion practice 13, no. 2 (2012): 159-164.

[10] OIE.https://www.oie.int/en/for-the-media/pressreleases/detail/article/oie-alerts-and-animal-health-information-nowavailable-on-your-smartphone-or-tablet/

[11] Gaia resources. https://www.gaiaresources.com.au/notify-nowvictoria-launches-animal-disease-notification-app/

[12] Davis, Fred D. "Perceived usefulness, perceived ease of use, and user acceptance of information technology." MIS quarterly (1989): 319-340.

[13] Blank, Steve, and Bob Dorf. The startup owner's manual: The stepby-step guide for building a great company. BookBaby, 2012.

[14] Philip, Kotler, Kartajaya Hermanwan, and Hooi Den Huan. Marketing For Competitiveness: Asia To The World-In The Age Of Digital Consumers. World Scientific, 2016.

[15] Luchs, Michael G., Scott Swan, and Abbie Griffin. Design thinking: New product development essentials from the PDMA. John Wiley \& Sons, 2015. 